\title{
Rotational Responses of Vestibular-Nerve Afferents Innervating the Semicircular Canals in the C57BL/6 Mouse
}

\author{
David M. Lasker, ${ }^{1}$ Gyu Cheol Han, ${ }^{2}$ Hong Ju Park, ${ }^{3}$ and Lloyd B. Minor ${ }^{1}$ \\ ${ }^{1}$ Department of Otolaryngology—Head E Neck Surgery, The Johns Hopkins University School of Medicine, Ross Building Suite \\ 710, 720 Rutland Ave., Baltimore, MD 21205, USA \\ ${ }^{2}$ Department of Otolaryngology—Head E Neck Surgery, The Gachon University of Medicine E Science, Graduate School of \\ Medicine, Gil Medical Center, 1198 Guwol-dong, Namdong-gu, Incheon 405-760, South Korea \\ ${ }^{3}$ Department of Otolaryngology-Head $\mathcal{E}$ Neck Surgery, The Konkuk University, Konkuk University Hospital, 4-12 Hwayang- \\ dong Gwangjin-gu, Seoul, 143-729, South Korea
}

Received: 17 October 2007; Accepted: 28 March 2008; Online publication: 13 May 2008

\begin{abstract}
Extracellular recordings were made from vestibularnerve afferents innervating the semicircular canals in anesthetized C57BL/6 mice ranging in age from 424 weeks. A normalized coefficient of variation was used to divide afferents into regular $\left(\mathrm{CV}^{*}<0.1\right)$ and irregular $\left(\mathrm{CV}^{*}>0.1\right)$ groups. There were three overall conclusions from this study. First, mouse afferents resemble those of other mammals in properties such as resting discharge rate and dependence of response dynamics on discharge regularity. Second, there are differences in mouse afferents relative to other mammals that are likely related to the smaller size of the semicircular canals. The rotational sensitivity of mouse afferents is approximately threefold lower than that reported for afferents in other mammals. One consequence of the lower sensitivity is that mouse afferents have a larger linear range for encoding head velocity. The long time constant of afferent discharge, which is a measure of low-frequency response dynamics, is shorter in mouse afferents than in other species. Third, juvenile mice (age 4-7 weeks) appear to lack a class of low-sensitivity, highly irregular afferents that are present in adult animals (age 10-24 weeks). By analogy to studies in the chinchilla, these irregular afferents with low sensitivities for lower rotational frequencies correspond to calyx-only afferents. These findings suggest that, although the calyx ending on to type I hair cells is morphologically complete in mice by the age of about 1 month, the physiological response properties in these juvenile animals are not equivalent to those in adults.
\end{abstract}

Correspondence to: David M. Lasker · Department of OtolaryngologyHead \& Neck Surgery - The Johns Hopkins University School of Medicine - Ross Building Suite 710, 720 Rutland Ave., Baltimore, MD 21205, USA. email: dlasker@jhmi.edu
Keywords: extracellular, development, irregular afferents, regular afferents

\section{INTRODUCTION}

The mouse with its extensively studied genetics and diverse assortment of known mutant strains has been an invaluable asset in analyzing almost every aspect of mammalian biology. Genetic manipulation as a means of understanding the underlying physiology can be particularly useful in the balance system because of the marked similarity in the anatomy and physiology among many mammalian species (Goldberg 2000; Desai et al. 2005a, b). Mice with specific mutations that affect balance function are relatively common (Anagnostopoulos 2002). Also, transgenic mice with specific changes to the physiology of the vestibular pathways are being created (Anagnostopoulos 2002). Previous work has examined the properties of the vestibulo-ocular reflex (VOR) in mice with and without genetic mutations. Studies of the effects of these mutations on processes such as learning and memory are providing fundamental new insights into vestibular and oculomotor control (Katoh et al. 1998; De Zeeuw et al. 1998; Stahl et al. 2000; van Alphen et al. 2001; Sun et al. 2001; van Alphen et al. 2002; Killian and Baker 2002; Goossens et al. 2004; Alagramam et al. 2005; Katoh et al. 2005; Boyden et al. 2006; Kimpo and Raymond 2007; Katoh et al. 2007; Aleisa et al. 2007).

In addition to these studies of the VOR, the responses of central vestibular neurons to rotations have been investigated in mice (Beraneck and Cullen 2007). Studies of vestibular hair cells in mice have defined the role of specific ion channels in sensory transduction (Rüsch and Eatock 1996; Eatock et al. 
1998; Rüsch et al. 1998; Géléoc et al. 2004). An understanding of the relationships between vestibular hair cells and central neurons requires knowledge of the physiology of vestibular-nerve afferents in mice. To that end, the first goal of this study is to define the responses of semicircular canal afferents to a wide range of rotational stimuli and to compare these responses to those that have been reported in other species.

Mice are able to fully open their eyes, support their own weight, and ambulate like adult mice by 2 weeks of age (Whelan 2003; Prusky et al. 2004). Recent studies in C57BL/6 mice have, however, shown that the gain of the VOR increases with age up until about 12 weeks (Shiga et al. 2005) and is substantially lower (when measured in darkness) in mice that are less than 30 days postgestational age in comparison to adult animals (Faulstich et al. 2004). An age-related decline in hearing has also been identified in C57BL/ 6 mice such that the threshold for eliciting the auditory brain stem response is elevated by the age of 24 weeks, and the mice are deaf by the age of 60 weeks (Hequembourg and Liberman 2001; Bartolomé et al. 2002; Henry 2002). Only a slight decrement in VOR gain was, however, noted at comparable ages (Shiga et al. 2005). Because of the changes observed in the VOR with age, a second goal of this study was to determine if the response properties or distribution of afferent groups differ with age (4-24 weeks) in the C57BL/ 6 mouse.

We report the resting discharge rate, normalized coefficient of variation of the interspike interval $\left(\mathrm{CV}^{*}\right)$, and response dynamics for sinusoidal rotations $(0.1-12 \mathrm{~Hz})$ in vestibular-nerve afferents recorded in the C57BL/ 6 mouse. The maximum sensitivity vectors for the three semicircular canals were also calculated. Transfer functions were fit to the averaged and individual afferent data. Though the individual properties of canal afferents in the mouse do not vary with the age of the mouse, there is an increase in the percentage of irregular afferents in adult when compared to juvenile mice.

\section{METHODS}

\section{Surgical procedure}

Data were obtained from 104 C57BL/6 mice obtained from Charles River Laboratories. Mice weighed between 12 and $36 \mathrm{~g}$. The ages of the mice used in this study ranged from 4-24 weeks. Juvenile mice were defined as mice that were between $4-7$ weeks of age ( 45 mice). Adult mice were defined as ranging from 1024 weeks of age (59 mice). Each animal was first anesthetized with a $100-\mathrm{mg} / \mathrm{kg}$ dosage of ketamine injected into the muscle of the hind leg. Next, a 10-mg/ $\mathrm{kg}$ dosage of xylazine was administered by intraperitoneal injection. Once anesthetized, the animals were maintained with a core body temperature of $36-37^{\circ} \mathrm{C}$ via an external servomechanism (FHC, model 40-90-8B). Saline (5\% of body weight) was injected subcutaneously during the experiment, and the heart and respiratory rate were monitored.

The animal was then placed in a stereotaxic frame such that the top of the skull was parallel to the horizontal plane. An incision was made at the back of the head. The ear canals were exposed so that the pins of the mounting device could be placed in the ear canal to keep the animal from moving. The snout of the mouse was then placed in a third mount. Care was taken to tighten the mounts without damaging the temporal bones. Our determination of canal plane angles revealed that the horizontal canals (see below) are pitched approximately $30^{\circ}$ upward in this position. As established by the data in Table 2, there was little variance in the canal plane angles calculated in the 42 adult animals used to determine these relationships. Next, the posterior neck muscles were detached from the skull for better exposure. While looking through a surgical microscope, a suboccipital craniectomy was made on the left side. Gray matter of the inferior semilunar lobule of cerebellum, paraflocculus, and flocculus was aspirated to expose the temporal bone. The brain stem was retracted to identify the vestibular nerve as it exited the internal auditory meatus. The superior and inferior branches of the vestibular nerve exit the temporal bone at different sites with the superior branch projecting more rostrally than the inferior nerve. All superior and horizontal canal afferents were recorded when the microelectrode was in the superior branch and all posterior canal afferents were recorded with the microelectrode in the inferior branch of the vestibular nerve. All surgical and experimental procedures were approved by the Animal Care and Use Committee of The Johns Hopkins University School of Medicine.

\section{Recording technique and data acquisition}

Glass micropipettes (WPI, model M1B100F-4) with impedances of 20-80 M $\Omega$ were filled with $3 \mathrm{M} \mathrm{NaCl}$ and used to make extracellular recordings from vestibular-nerve afferents. These microelectrodes were brought into position over the nerve using a minimanipulator (You, model US-3F). This minimanipulator could maneuver in three dimensions and was attached to a microdrive (Narishige International USA, model MO-22) mounted on the stereotaxic frame. The micropipette was advanced using the microdrive until it entered the superior or inferior division of the vestibular nerve as it emerged from the 
internal auditory meatus. Afferents included in this study had a sustained resting discharge rate. It is important to note that afferents that are silent at rest would not be identified with this technique. Signals from the nerve were amplified and band-pass filtered (300-3 kHz; Dagan, model 2400A). Spikes were identified with a window discrimination method (Mentor, model N-750). An external auditory speaker was used to discern the activity of neurons. The timing of action potentials was recorded through a digital event channel with a resolution of 100 ns (CED, micro1401). In addition, the voltage from the microelectrode was digitized with a 16 -bit $\mathrm{A} / \mathrm{D}$ converter with a sample rate $5 \mathrm{kHz}$ for off-line comparison with the spike times. The angular head position was obtained using a high-resolution digital encoder that was also digitized with a sample rate of $2 \mathrm{kHz}$. These signals were then recorded on a PC for offline analysis.

\section{Determination of maximum sensitivity vectors}

The animal was secured in the stereotaxic frame, which was then attached to a position servomotor that rotated about the earth-vertical axis (Acutronic, ACT200). The superstructure was designed as a Fick gimbal that was also mobile in the pitch and roll axes. In a Fick gimbal, a final rotational position is completely characterized by a rotation around the vertical axis (yaw), followed by a rotation about the horizontal axis (pitch), and finally, a rotation around the line of sight (roll) (Haslwanter 1995). Once an afferent was isolated, a series of manual rotations was used to determine whether the afferent innervated a semicircular canal or an otolith organ. For canal afferents, the animal was rotated manually at approximately $0.5 \mathrm{~Hz}$ at a minimum of five different pitch and roll angles $\left(0^{\circ}, \pm 20^{\circ}\right.$ nose up and down, $\pm 20^{\circ}$ right ear up and down). Most of the afferents were also rotated at $0.5 \mathrm{~Hz}$ at $\pm 10^{\circ}, 30^{\circ}$, and $40^{\circ}$ at those four different angles. The maximum sensitivity vector for each canal afferent was calculated from these data. We first calculated a vector normal to the plane of a particular canal for each unit by solving a set of simultaneous equations (Eq. 1)

$$
[\mathrm{S}]=[\text { Rfick }] *[\mathrm{z}] \cdot[\mathrm{N}]
$$

where $[S]$ - the vector of sensitivities obtained at each set of angles

[Rfick] - the rotation matrix in Fick coordinates for each set of angles

$[z]$ - the vector normal to the earth horizontal axis,

$$
\left[\begin{array}{l}
0 \\
0 \\
1
\end{array}\right]
$$

$[N]$ - the vector normal to the plane of a canal based on one unit

*-denotes matrix multiplication

- -denotes the dot product

After the vector normal to the plane for a particular unit had been determined, we calculated the optimal angles from rotations of the Fick gimbal used to place that particular canal in the earthhorizontal plane, $\psi_{\mathrm{F}}[(+)$ right ear down, (-) left ear down $)]$ and $\varphi_{\mathrm{F}}[(+)$ nose down, (-) nose up], and the maximum sensitivity for that afferent. Planar equations were derived from these measurements. The axis for these equations is defined from the perspective of the mouse's head with the yaw axis pointing up, the roll axis pointing out of the nose, and the pitch axis pointing out the left ear.

\section{Rotational stimulation}

Once a canal afferent was identified, the animal was placed via the Fick gimbal such that the afferent was within $20 \%$ of the maximum sensitivity for that canal plane. Animals were then rotated at frequencies ranging from $0.1-12 \mathrm{~Hz}$ at peak velocities of $25^{\circ} / \mathrm{s}$ via the position servomotor. To confirm that sensitivity did not change with peak head velocity, we also recorded the responses of a subset of the afferents at multiple peak head velocities $\left(25-75^{\circ} / \mathrm{s}\right.$; see "Linearity of responses"). Angular head velocity was obtained by differentiating the signal from an angular position transducer mounted to the shaft of the turntable. The accuracy of the turntable position was confirmed via a linear accelerometer mounted eccentric to the head of the mouse. The phase difference between the accelerometer and the table position was $180 \pm 3^{\circ}($ mean $\pm \mathrm{SD})$ at all frequencies. Responses during each sinusoid of rotation were recorded for $30 \mathrm{~s}$.

\section{Data analysis}

A cycle histogram was created from records of average spike rates. A least squares fit was performed to the first harmonic of the averaged velocity response and cycle histogram to calculate the sensitivity and phase at each frequency. Cutoff was observed in less than 5\% of the afferents recorded for any stimulus condition. In the small subset in which cutoff was observed, the empty bins of the response cycle histogram were treated as regions void of data as described previously (Highstein et al. 1996). The sensitivity was then calibrated using either the individual canal's maximum sensitivity vector or the derived maximum sensitivity vector for that canal plane. The order of the resulting transfer function (i.e., number of poles and zeros) was determined using the Bayesian Infor- 


\begin{tabular}{lccc}
\hline \multicolumn{4}{c}{ TABLE 1 } \\
\hline \multicolumn{4}{c}{ Power-law constants (from Eq. 2) } \\
interspike interval (ISI) & to CV ${ }^{*}$ \\
\hline ISI (s) & No. of units & $A$ & $b$ \\
\hline 0.011 & 8 & 0.36 & 0.70 \\
0.014 & 21 & 1.06 & 1.05 \\
0.017 & 31 & 1.04 & 0.96 \\
0.021 & 38 & 1.16 & 0.97 \\
0.025 & 47 & 1.30 & 0.95 \\
0.031 & 51 & 1.28 & 0.85 \\
0.037 & 48 & 1.50 & 0.84 \\
0.043 & 42 & 1.96 & 0.88 \\
0.049 & 35 & 1.73 & 0.78 \\
0.055 & 31 & 1.70 & 0.73 \\
0.061 & 25 & 1.44 & 0.66 \\
0.067 & 22 & 1.42 & 0.63 \\
0.075 & 20 & 1.44 & 0.61 \\
0.083 & 18 & 1.35 & 0.55 \\
0.091 & 16 & 2.49 & 0.76 \\
0.099 & 15 & 3.38 & 0.87 \\
\hline
\end{tabular}

mation Criterion (BIC) to obtain the best fit to the data while minimizing the complexity of the fit (Galiana et al. 1995; Cullen et al. 1996; Minor et al. 1999). Individual transfer functions were then fit to the raw data for each afferent. The number of poles and zeroes of the resulting transfer function fits was set so that it never exceeded the order of the fits to the average transfer function.

\section{Coefficient of variation}

Afferents were classified according to the regularity of their background discharge rate by measuring the coefficient of variation (CV). Because CV is dependent upon the interspike interval, mouse otolith afferents were recorded separately and used to calculate a normalized coefficient of variation at a mean interspike interval of $15 \mathrm{~ms}\left(\mathrm{CV}^{*}\right)$. Otolith afferents are suited for establishing the relationships between $\mathrm{CV}$ and $\mathrm{CV}^{*}$ because their discharge rate varies with head position but remains constant in each position. In brief, 87 otolith afferents from 25 mice were recorded at various angles of pitch and roll. Discharge rate was measured during the period of 1 to $5 \mathrm{~s}$ after the animal was moved into each position. These units were then used to create power-law regressions to determine coefficients that related $\mathrm{CV}^{*}$ to $\mathrm{CV}$. These power-law regressions are functions of interspike interval (ISI) and have the following form:

$$
\mathrm{CV}=\mathrm{a} \cdot\left(\mathrm{CV}^{*}\right)^{\mathrm{b}}
$$

Separate values of $a$ and $b$ were calculated for 16 values of ISI, ranging from 8 to $100 \mathrm{~ms}$ (Table 1 ).
Figure 1 shows the relationship between CV and ISI for all semicircular canal afferents in the study. Curves depicting the change in CV with ISI (calculated from data in otolith afferents) at five values of $\mathrm{CV}^{*}$ are also plotted. This technique for calculating $\mathrm{CV}^{*}$ is the same as that used in previous studies for the squirrel monkey (Goldberg et al. 1984) and the chinchilla (Baird et al. 1988; Hullar et al. 2005). Afferents were then categorized into two groups, regular $\left(\mathrm{CV}^{*}<0.1\right)$ and irregular $\left(\mathrm{CV}^{*}>0.1\right)$.

\section{RESULTS}

We recorded from a total of 443 afferents that innervated the semicircular canals on the left side in C57BL/6 mice. Afferents innervating the posterior canal were found exclusively in the inferior division of the vestibular nerve. When recording in the superior division of the vestibular nerve, we were able to determine immediately if an afferent innervated the horizontal or superior canal based on the polarity of discharge rate with the rotation of the animal around the earth-vertical axis. All horizontal afferents increased their firing rate when moving ipsilateral to the recording side and decreased their firing when moving contralateral to the recording side when the animal was positioned such that the horizontal canals were aligned parallel to the earth-horizontal plane. In this position, superior canal afferents did the oppo-

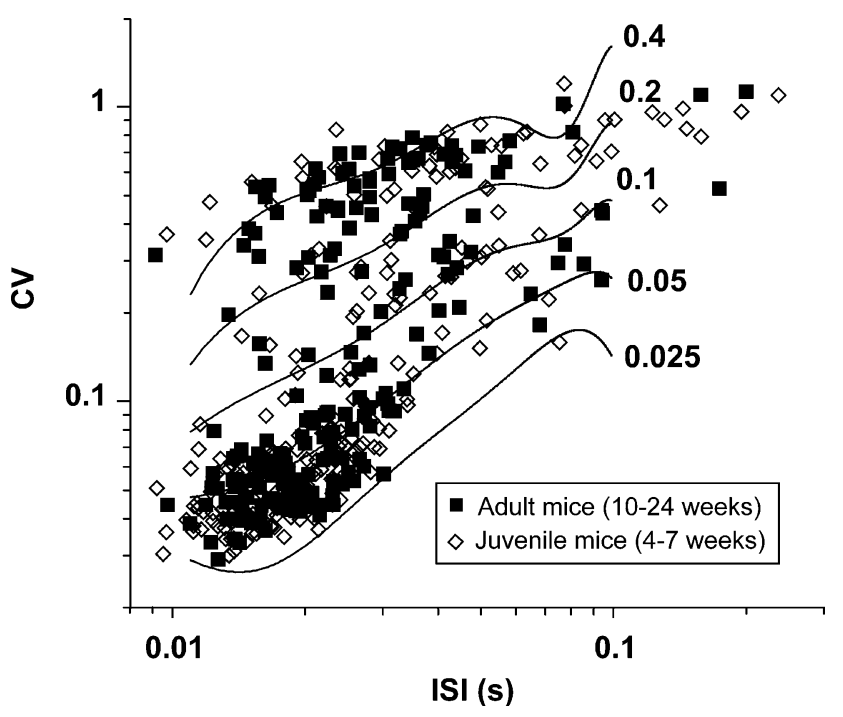

FIG. 1. Values for the coefficient of variation (CV) and the corresponding interspike interval (ISI) obtained from the analysis of a 5-s period of resting activity from semicircular canal afferents in juvenile and adult mice. Power law regressions obtained from data in otolith afferents as described in "Methods" were used to create curves relating the ISI and the CV for five values of $\mathrm{CV}^{*}(0.025,0.05$, $0.1,0.2,0.4)$. 
site: increased firing rate for contralateral rotations and decreased for ipsilateral rotations. As described in the "Methods," the animal was next positioned in the plane needed to produce near maximum modulation of the afferent with rotation. We analyzed the resting discharge rate, normalized coefficient of variation of the interspike interval $\left(\mathrm{CV}^{*}\right)$, and response dynamics for sinusoidal rotations $(0.1-12 \mathrm{~Hz})$. An example of the discharge characteristics of two afferents is shown in Figure 2. Transfer functions were fit to the averaged and to individual afferent data.

\section{Geometry of canal planes}

Maximum sensitivity vectors were computed from a total of 123 canal afferents recorded from the left vestibular nerve in 42 adult mice. The afferents supplied the following semicircular canals: 72 to the superior, 34 to the horizontal, and 22 to the posterior. The average Fick angles derived from each unit are given in Table 2. Planar equations were determined from the measurements of the Fick angles. Internal angles between pairs of semicircular canals were derived from these planar equations (Table 2). The following angles were calculated: $87^{\circ}$ between the horizontal and superior canal, $85^{\circ}$ between the horizontal and posterior canal, and $97^{\circ}$ between the posterior and superior canal. Computations based upon our functional technique resulted in estimates of canal planes that were similar to the results from high-voltage X-ray computed tomography of the temporal bones (Calabrese and Hullar 2006).

\section{Linearity of responses}

In adult mice, we recorded responses at multiple frequencies $(0.2,4,8 \mathrm{~Hz})$ and peak head velocities $\left(25,50,75^{\circ} / \mathrm{s}\right)$ in 19 afferents from nine mice to test whether the sensitivity or phase varied with peak head

\section{REGULAR}

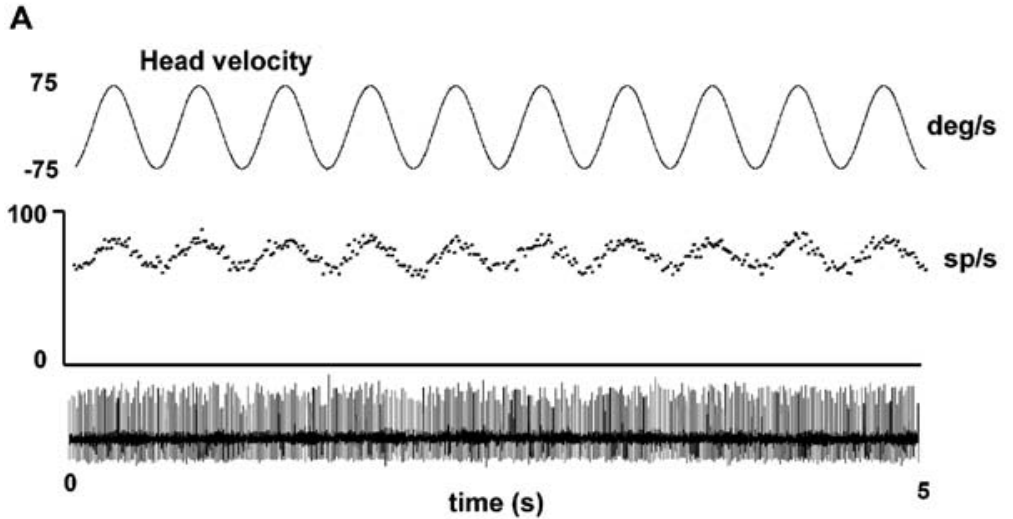

B

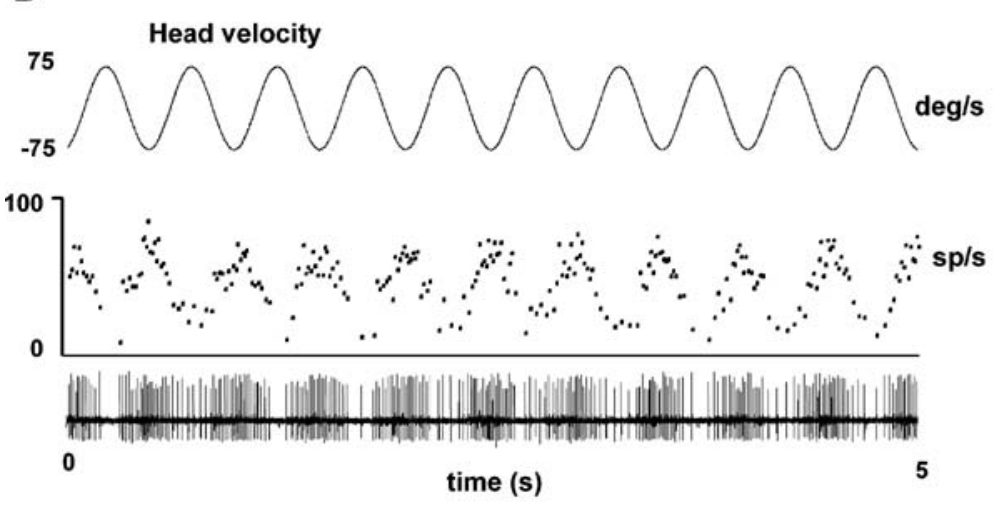

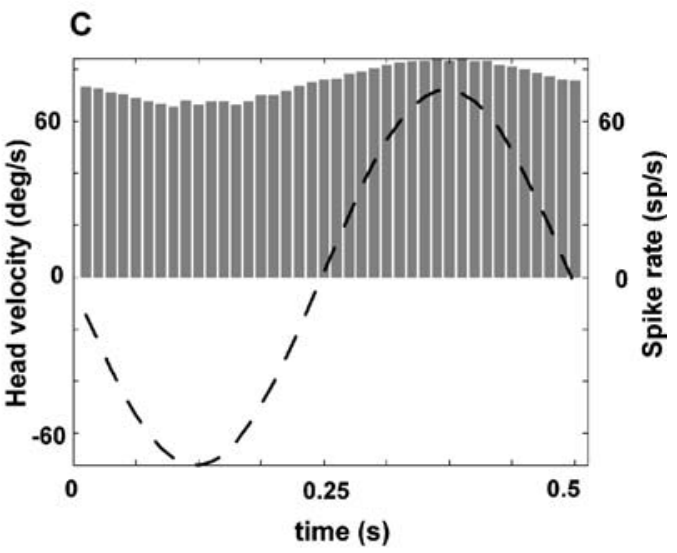

D

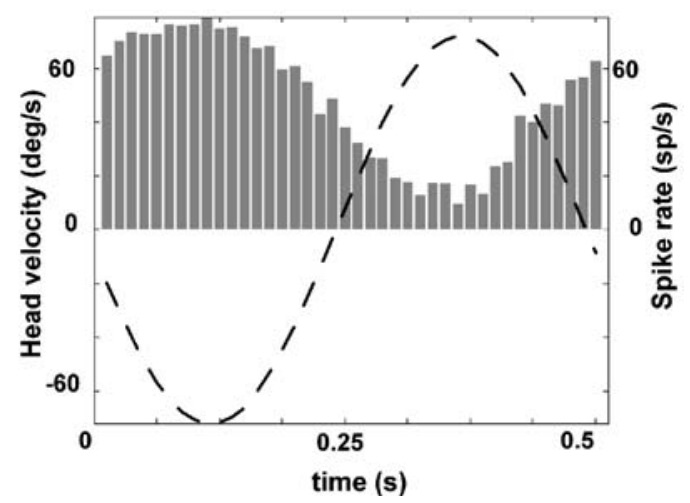

FIG. 2. Modulation of discharge rate during sinusoidal rotations at $2 \mathrm{~Hz}$ with maximum velocity of $\pm 75 \% \mathrm{~s}$ in a regular $\left(\mathrm{CV}^{*}=0.0315\right.$, superior canal, $\mathbf{A})$ and irregular $\left(\mathrm{CV}^{*}=0.27\right.$, horizontal canal, B) afferent from a $\mathrm{C} 57 \mathrm{BL} / 6$ mouse. The instantaneous firing rate is plotted, below the head velocity trace. The voltage trace from the microelectrode recording showing the action potentials is plotted below the spike rate trace. The average bin histogram is plotted for the same regular $(\mathbf{C})$ and irregular $(\mathbf{D})$ afferent. The dashed trace in $\mathbf{C}$ and $\mathbf{D}$ is the superimposed average head velocity signal. 
TABLE 2

Fick angles for the sequence of rotations placing a canal in the earth-horizontal plane and the corresponding planar equations derived from these angles for the left side

\begin{tabular}{llrrrr}
\hline Type & $N$ & \multicolumn{1}{l}{$\psi_{F}$} & \multicolumn{1}{c}{$\varphi_{F}$} & Planar equation (functionally derived) & Planar equation (Calabrese and Hullar 2006) \\
\hline Left anterior & 72 & $-61.3 \pm 4.05$ & $-30.0 \pm 8.27$ & $-0.500 x+0.759 y-0.417 z$ & $-0.596 x+0.702 y-0.369 z$ \\
Left horizontal & 34 & $2.56 \pm 9.29$ & $33.0 \pm 7.07$ & $-0.544 x+0.037 y+0.838 z$ & $-0.521 x-0.053 y+0.843 z$ \\
Left posterior & 22 & $60.6 \pm 6.16$ & $-32.5 \pm 14.6$ & $-0.538 x-0.734 y-0.414 z$ & $-0.350 x-0.783 y-0.500 z$ \\
\hline
\end{tabular}

Planar equations derived from $x$-ray tomography studies of Calabrese and Hullar (2006) are also given. The Fick angles were defined as follows: $\psi_{\mathrm{F}}[(+)$ right ear down, (-) left ear down] and $\varphi_{\mathrm{F}}[(+)$ nose down, (-) nose up]

velocity. We also recorded responses in seven of these 19 afferents (four mice) at $12 \mathrm{~Hz}$ with peak head velocities at 25 and $50^{\circ} / \mathrm{s}$.

To determine whether peak velocity had any effect on sensitivity and phase, we compared responses using a linear multiple analysis of variance model. The means of the sensitivities and phases were significantly different based on the $\mathrm{CV}^{*}$ and frequency, as is expected based upon studies in other species (Goldberg et al. 1984; Baird et al. 1988; Hullar et al. 2005). There was no significant difference for the
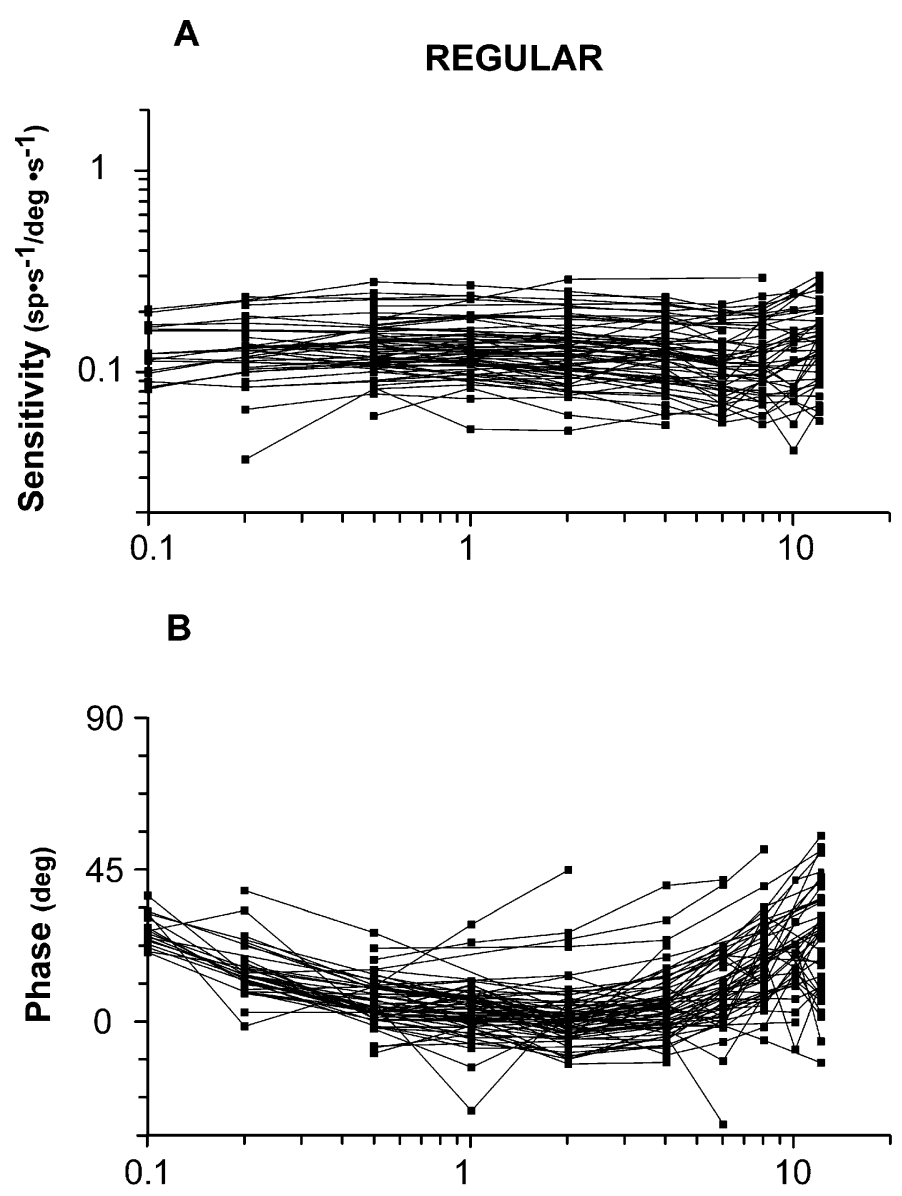

sensitivity $(p>0.1)$ or phase $(p>0.3)$ based on peak head velocity for an individual afferent at a specified frequency. Therefore, we concluded that peak head velocity had no effect on the sensitivity and phase of individual afferents at single frequencies.

\section{Static firing properties}

We obtained a resting discharge rate and a corresponding coefficient of variation in a total of 443 canal afferents recorded in 104 mice at ages 4-

\section{C}

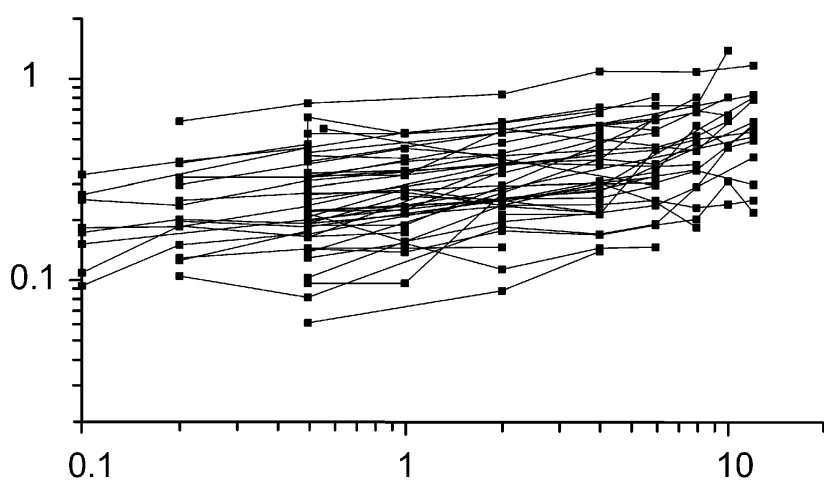

D

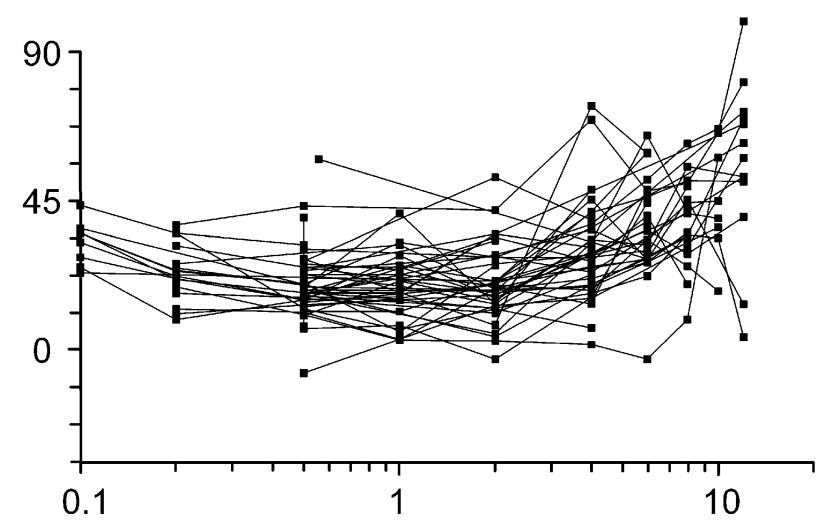

\section{Frequency $(\mathrm{Hz})$}

FIG. 3. Sensitivity and phase re head velocity for regular afferents $(\mathbf{A}, \mathbf{B})$ and for irregular afferents $(\mathbf{C}, \mathbf{D})$ are plotted versus frequency for mice ranging in age from 4-24 weeks. 
TABLE 3

The average sensitivity and phase lead with respect to head velocity at each frequency of rotation

\begin{tabular}{|c|c|c|c|c|c|c|}
\hline \multirow[b]{2}{*}{ Frequency $(\mathrm{Hz})$} & \multicolumn{3}{|c|}{ Regular } & \multicolumn{3}{|c|}{ Irregular } \\
\hline & $\begin{array}{l}\text { Sensitivity } \\
\left(\mathrm{s} p \cdot \mathrm{s}^{-1} \text { per degree } \cdot \mathrm{s}^{-1}\right)\end{array}$ & $\begin{array}{l}\text { Phase } \\
\text { (degree) }\end{array}$ & No. of afferents & $\begin{array}{l}\text { Sensitivity } \\
\left(s p \cdot s^{-1} \text { per degree } \cdot s^{-1}\right)\end{array}$ & $\begin{array}{l}\text { Phase } \\
\text { (degree) }\end{array}$ & No. of afferents \\
\hline 0.1 & $0.12 \pm 0.04$ & $26 \pm 4$ & 17 & $0.20 \pm 0.09$ & $32 \pm 7$ & 11 \\
\hline 0.2 & $0.13 \pm 0.04$ & $15 \pm 7$ & 29 & $0.26 \pm 0.07$ & $22 \pm 9$ & 17 \\
\hline 0.5 & $0.14 \pm 0.05$ & $6 \pm 7$ & 66 & $0.27 \pm 0.13$ & $20 \pm 9$ & 47 \\
\hline 1 & $0.13 \pm 0.05$ & $3 \pm 6$ & 38 & $0.28 \pm 0.14$ & $20 \pm 10$ & 23 \\
\hline 2 & $0.13 \pm 0.05$ & $1 \pm 8$ & 66 & $0.30 \pm 0.14$ & $21 \pm 11$ & 47 \\
\hline 4 & $0.13 \pm 0.04$ & $4 \pm 5$ & 63 & $0.37 \pm 0.14$ & $27 \pm 14$ & 39 \\
\hline 6 & $0.13 \pm 0.07$ & $7 \pm 9$ & 37 & $0.39 \pm 0.14$ & $38 \pm 15$ & 27 \\
\hline 8 & $0.14 \pm 0.04$ & $16 \pm 5$ & 47 & $0.45 \pm 0.15$ & $38 \pm 15$ & 21 \\
\hline 12 & $0.15 \pm 0.06$ & $23 \pm 10$ & 44 & $0.53 \pm 0.22$ & $48 \pm 18$ & 19 \\
\hline
\end{tabular}

24 weeks (Fig. 1). The superior canal was innervated by 200 of these units, 182 units supplied the horizontal canal and 61 units innervated the posterior canal. $\mathrm{CV}^{*}$ was calculated and units were classified as either regular $\left(\mathrm{CV}^{*}<0.1\right)$ or irregular $\left(\mathrm{CV}^{*}>0.1\right.$; Goldberg et al. 1984; Baird et al. 1988; Hullar et al. 2005). There were 12 afferents that had resting discharge rates $<10.1$ spikes per second and five units that had resting discharge rates $>90.1$ spikes per second and could not, therefore, be normalized. All subsequent analysis was performed on the remaining 426 afferents. Linear regression analysis revealed that the resting rate and the coefficient of variation did not vary with the age of the mouse $\left(R^{2}<0.1\right)$. The resting rate for regular afferents was $55.3 \pm 19.1$ spikes per second (mean $\pm \mathrm{SD} ; n=277$ ). The resting rate for irregular afferents was $37.3 \pm 17.7$ spikes per second $(n=149)$, which was less than that of regular afferents $(p<0.01)$. The average $\mathrm{CV}^{*}$ for regular and irregular afferents was $0.05 \pm 0.02$ and $0.35 \pm 0.13$, respectively.

\section{Response dynamics}

Afferents for which responses to sinusoidal rotations were measured at $0.5,2 \mathrm{~Hz}$ and at least one other frequency were included in the analysis of response dynamics (40 mice, Fig. 3). Linear regression analysis at each frequency revealed that the sensitivity and the phase did not vary with the age of the mouse $\left(R^{2}<\right.$ 0.1 ). The average sensitivity and phase lead with respect to head velocity at each frequency are listed in Table 3 and plotted in Figure 4. At every frequency tested, there was a difference between sensitivity and phase for regular when compared to irregular afferents $(p<0.001)$.

Transfer functions were fit to the average sensitivity and phase to describe the dependence of response dynamics on frequency. We fit higher order terms (different combinations of poles and zeros) and determined from the values obtained for the BIC that the resulting data were best fit with a transfer function of the form:

$$
\mathrm{DR}=\frac{g \cdot\left(t_{c 1} s\right)\left(t_{z} s+1\right) \cdot H v}{\left(t_{c 1} s+1\right)}
$$

where DR is discharge rate and $\mathrm{Hv}$ is angular head velocity. The average values for $g, t_{\mathrm{c} 1}$, and $t_{\mathrm{z}}$ are shown in Table 4.

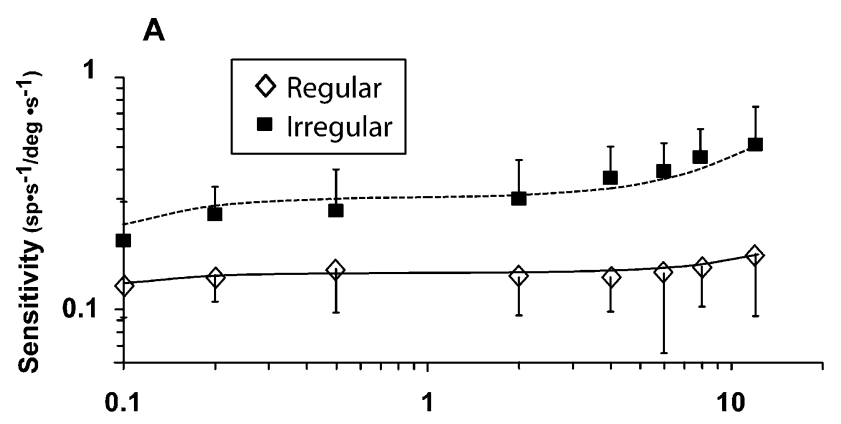

B

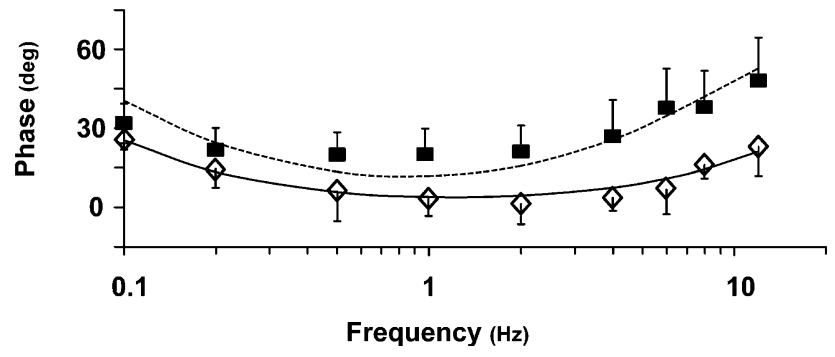

FIG. 4. Irregular afferents have a greater sensitivity and larger phase lead re head velocity at higher frequencies when compared to regular afferents. Average sensitivity $(\mathbf{A})$ and phase lead re head velocity $(\mathbf{B})$ are plotted versus frequency for rotations at $\pm 25 \%$ with standard deviations at each data point. Fits from a least squares analysis of the data are plotted with a solid trace for regular afferents and with a dashed trace for irregular afferents. 
TABLE 4

Parameters obtained for best fits to normalized data and individual afferent data from the transfer function of the form $g\left(t_{\mathrm{c} 1} s\right)\left(t_{\mathrm{z}} s+1\right) /\left(t_{\mathrm{c} 1} s+1\right)$

\begin{tabular}{|c|c|c|c|c|c|c|}
\hline \multirow[b]{2}{*}{ Afferent category } & \multicolumn{2}{|c|}{$g\left(s p \cdot s^{-1}\right.$ per degree $\left.\cdot s^{-1}\right)$} & \multicolumn{2}{|c|}{$t_{c 1}(s)$} & \multicolumn{2}{|c|}{$t_{z}(s)$} \\
\hline & $\begin{array}{l}\text { Best fit to } \\
\text { normalized data }\end{array}$ & $\begin{array}{l}\text { Fit to individual } \\
\text { afferents }\end{array}$ & $\begin{array}{l}\text { Best fit to } \\
\text { normalized data }\end{array}$ & $\begin{array}{l}\text { Fit to individual } \\
\text { afferents }\end{array}$ & $\begin{array}{l}\text { Best fit to } \\
\text { normalized data }\end{array}$ & $\begin{array}{l}\text { Fit to individual } \\
\text { afferents }\end{array}$ \\
\hline Regular & 0.13 & $0.13 \pm 0.06$ & 3.3 & $3.7 \pm 1.3$ & 0.005 & $0.006 \pm 0.004$ \\
\hline Irregular & 0.31 & $0.29 \pm 0.14$ & 1.9 & $2.2 \pm 1.3$ & 0.018 & $0.020 \pm 0.013$ \\
\hline
\end{tabular}

The form of this transfer function is identical to other canal afferent transfer functions except for the lack of a high-frequency pole used to model the ratio of the viscous damping coefficient to the moment of inertia of the endolymph (Fernández and Goldberg 1971; Baird et al. 1988; Hullar and Minor 1999; Hullar et al. 2005). Using the value for the internal radius of the membranous canal obtained from Jones and Spells (1963), we determined that the mouse should have a high-frequency pole with a short time constant on the order of $0.001 \mathrm{~s}$. This calculation was based on the torsion pendulum model where the short time constant should be proportional to the square of the internal radius of the membranous canal. Estimates of the value of this time constant in monkeys and humans are 0.003 and $0.005 \mathrm{~s}$, respectively (Fernández and Goldberg 1971). The square of the internal radius in the mouse has been measured to be $0.005 \mathrm{~mm}^{2}$ (Jones and Spells 1963). This value is approximately threefold less than in the monkey. The effect of this pole would be negligible at the frequencies of rotation used in our experiments. For example, this pole would cause a phase lag of only $3^{\circ}$ at $12 \mathrm{~Hz}$. Empirical calculation of the value for this short time constant would require rotations at frequencies higher than those used in this study.

\section{Distribution of afferents between juvenile and adult mice}

Although there was no relationship between the age of the mouse and the resting discharge rate or response dynamics of afferents innervating the semicircular canals, there were fewer irregular afferents in juvenile mice. To evaluate the relationship between age and the distribution of afferents according to discharge regularity, we divided mice into two groups based upon age: juvenile (47 weeks) and adult (10-24 weeks). Of the 426 afferents, 214 were recorded in juveniles and 212 in adults. In juveniles, $149(70 \%)$ were classified as regular and $65(30 \%)$ were classified as irregular. Of the 212 afferents that were recorded in adults, 128 $(60 \%)$ were classified as regular and $84(40 \%)$ were classified as irregular. There was a higher proportion of irregular afferents in adult when compared to juvenile mice (Fig. $5 ; p<0.05$ ).

\section{Sinusoidal responses at $2 \mathrm{~Hz}$ for juvenile} and adult mice

In a previous study in the chinchilla, the regularity of discharge and the dynamics at $2 \mathrm{~Hz}$ have been correlated with the morphology of the endings of vestibular afferents on hair cells (Baird et al. 1988). For comparison with data in chinchillas, Figure 6 shows the sensitivity and phase of afferents recorded at $2 \mathrm{~Hz}$ as functions of $\mathrm{CV}^{*}$. Table 5 shows that, for responses measured at $2 \mathrm{~Hz}$, there was no difference with respect to age for sensitivity and phase. Although there was no age-dependent difference between the sensitivity of irregular afferents, there was a larger standard deviation for sensitivity in adults $(0.21)$ than in juveniles $(0.11 ; p<0.01)$. This larger range of sensitivities in adults suggests a greater diversity of responses. In particular, juvenile mice appear to lack a separate population of lowsensitivity irregular afferents.

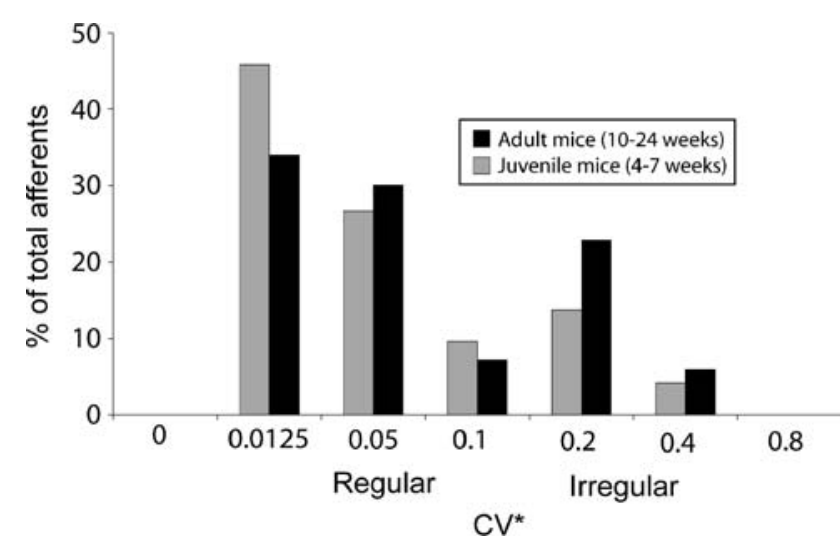

FIG. 5. Adult mice have a higher proportion of irregular afferents than do juvenile mice. The histogram shows the distribution of the normalized coefficient of variation for data obtained from 214 afferents recorded in juvenile mice and 212 afferents recorded in adult mice. 


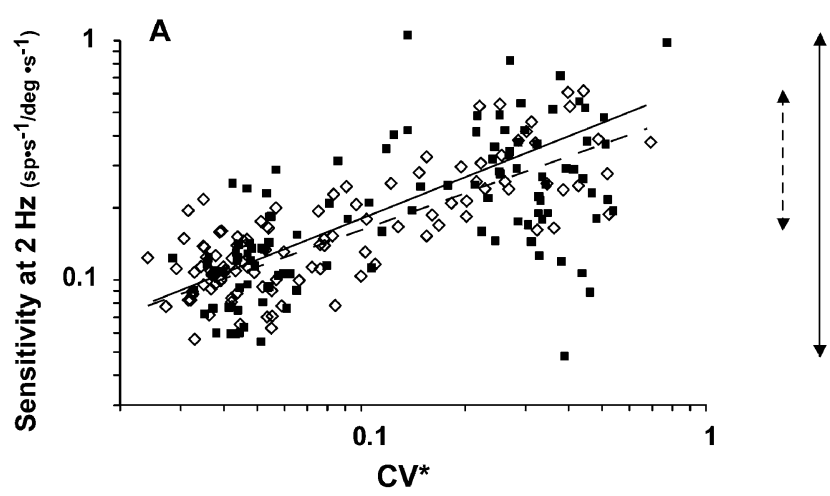

B

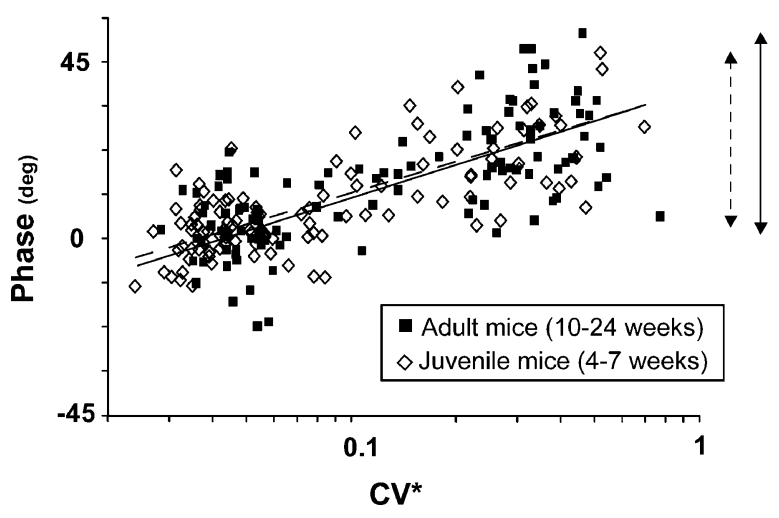

FIG. 6. The range of values for rotational sensitivity of irregular afferents is larger in adult when compared to juvenile mice. Sensitivity (A) and phase lead re velocity (B) at $2 \mathrm{~Hz}$ versus $\mathrm{CV}^{*}$ for juvenile and adult mice are plotted. Fits to the data in adult mice are solid. Fits to the data in juvenile mouse are dashed. Sidebars for adult (solid) and juvenile (dashed) mice have been plotted to show the difference in the ranges of sensitivity and phase at $2 \mathrm{~Hz}$ for irregular afferents.

To determine how the sensitivity at $2 \mathrm{~Hz}$ varied with discharge regularity, we fit the data with a regression equation of the form:

$G_{2 \mathrm{~Hz}}=\mathrm{a} \cdot\left(\mathrm{CV}^{*}\right)^{\mathrm{b}}$

$G_{2 \mathrm{~Hz}}=(0.44 \pm 0.12)\left(\mathrm{CV}^{*}\right)^{0.39 \pm 0.058}, R^{2}=0.34($ adult $)$

$G_{2 \mathrm{~Hz}}=(0.48 \pm 0.087)\left(\mathrm{CV}^{*}\right)^{0.47 \pm 0.049}, R^{2}=0.58($ juvenile $)$

Multiple regression on the above data for sensitivity revealed that there was no difference in the value for the coefficients of $a(p>0.2)$ and $b(p>0.1)$.

An equation of the following form was fit to the phase at $2 \mathrm{~Hz}$ with respect to $\mathrm{CV}^{*}$ :

$$
\begin{aligned}
P_{2 \mathrm{~Hz}} & =\mathrm{a}+\mathrm{b} \cdot\left(\log \mathrm{CV}^{*}\right) \\
P_{2 \mathrm{~Hz}} & =(25.2 \pm 10.5) \log \left(\mathrm{CV}^{*}\right)+(36.4 \pm 13), \\
R^{2} & =0.48(\text { adult }) \\
P_{2 \mathrm{~Hz}} & =(24.5 \pm 10.0) \log \left(\mathrm{CV}^{*}\right)+(34.5 \pm 10.9), \\
R^{2} & =0.55(\text { juvenile })
\end{aligned}
$$

Multiple regression on the above data for phase revealed that there was no difference in the value for the coefficients of $a(p>0.6)$ and $b(p>0.5)$.

\section{DISCUSSION}

We found that the dependence of response dynamics on discharge regularity was similar in the mouse to that reported in other species. The striking difference between findings in mice and those in other mammalian species was the two- to fourfold lower rotational sensitivities of afferents in mice when compared to the sensitivities measured in monkeys (Fernández and Goldberg 1971; Ramachandran and Lisberger 2006; Sadeghi et al. 2007), chinchillas (Baird et al. 1988; Hullar and Minor 1999; Hullar et al. 2005), and cats (Tomko et al. 1981). Lower phase leads with respect to head velocity were also noted in responses to highfrequency rotations $(>4 \mathrm{~Hz})$ in mice when compared to these other species.

The mean resting discharge rate was higher for regular than irregular afferents. The resting rate of afferents in mice was comparable to that previously reported in chinchillas, cats, and gerbils for both groups of afferents (Baird et al. 1988; Hullar et al. 2005; Tomko et al. 1981; Murofushi and Curthoys 1997) but lower than that reported in monkeys (Fernández and Goldberg 1971; Ramachandran and Lisberger 2006; Sadeghi et al. 2007). The dependence of sensitivity and phase on rotational frequency is similar in the mouse to that reported in cats, chinchillas, and other mammals. Indeed, a transfer function with a form comparable to that used to fit data in these other species was also found to be appropriate for mice. The long time constant derived from these fits to the data was substantially shorter (3.7 s) than that measured previously in monkeys $(5.7 \mathrm{~s}$; Fernández and Goldberg 1971) and somewhat shorter than that reported in chinchillas (4.3 s; Baird et al. 1988). These differences in time constants were predicted because the semicircular canals of the mouse have a smaller radius of curvature than for the canals in monkeys or chinchillas (Jones and Spells 1963).

We found an increase in the relative proportion of irregular afferents in adult (10-24 weeks) in comparison to juvenile (4-7 weeks) mice. There was also a greater range of irregular afferent sensitivities in adult when compared to juvenile animals. The potential significance of this finding with respect to the late development of the distinctive properties of calx-only irregular afferents is discussed below.

\section{Linearity of responses}

Studies in the chinchilla (Hullar and Minor 1999) and the toadfish (Boyle and Highstein 1990) have shown that regular afferents are not driven into inhibitory cutoff over a broad range of frequencies and velocities. Irregular afferents, in contrast, are more susceptible to inhibitory cutoff (Fernández and 
TABLE 5

There is no difference between the sensitivity and phase lead with respect to head velocity for juvenile in comparison to adult mice during $2 \mathrm{~Hz}$ rotations

\begin{tabular}{|c|c|c|c|c|c|c|}
\hline \multirow[b]{2}{*}{ Mouse } & \multicolumn{3}{|c|}{ Regular } & \multicolumn{3}{|c|}{ Irregular } \\
\hline & $\begin{array}{l}\text { Sensitivity } \\
\left(\mathrm{sp} \cdot \mathrm{s}^{-1} \text { per deg } \cdot \mathrm{s}^{-1}\right)\end{array}$ & $\begin{array}{l}\text { Phase } \\
\text { (degree) }\end{array}$ & No. of afferents & $\begin{array}{l}\text { Sensitivity } \\
\left(s p \cdot s^{-1} \text { per degree } \cdot s^{-1}\right)\end{array}$ & $\begin{array}{l}\text { Phase } \\
\text { (degree) }\end{array}$ & No. of afferents \\
\hline Juvenile (40 mice) & $0.12 \pm 0.05^{*}$ & $2 \pm 8^{* *}$ & 53 & $0.28 \pm 0.11^{* *}$ & $23 \pm 12^{* *}$ & 30 \\
\hline Adult (55 mice) & $0.14 \pm 0.06^{*}$ & $0 \pm 7^{* *}$ & 67 & $0.33 \pm 0.21^{* *}$ & $21 \pm 11^{* *}$ & 59 \\
\hline
\end{tabular}

The $p$ values for the comparisons indicated by superscripts are as follows: ${ }^{*} p>0.08,{ }^{* *} p>0.2$

Goldberg 1971, 1976; Hullar et al. 2005). Our analysis of variance relating the sensitivity and phase to peak head velocity showed that the there were very few nonlinearities in the responses. The response linearity was maintained in these afferents because the resting discharge rate was relatively high and sensitivities were low. For example, at $8 \mathrm{~Hz}$, the average sensitivity was 0.45 spikes per second/degree per second for the most sensitive irregular afferents. A rotation at $75^{\circ} / \mathrm{s}$ would cause a peak change in discharge rate of only 34 spikes per second, which is below the average resting rate ( 37 spikes per second) for irregular afferents.

These findings indicate that the range of frequencies and velocities of head rotation over which canal afferents encode motion in the mouse is substantially greater than that in other species (Fernández and Goldberg 1971; Boyle and Highstein 1990; Hullar and Minor 1999; Hullar et al. 2005).

\section{Resting discharge properties}

The resting discharge properties of vestibular afferents were similar to other mammals (Fernández and Goldberg 1971; Baird et al. 1988; Hullar and Minor 1999; Hullar et al. 2005). The mean resting rate of regular afferents in the chinchilla was between 50-60 spikes per second in comparison to 55 spikes per second in the mouse (Hullar and Minor 1999; Hullar et al. 2005). The mean resting rate of irregular afferents in the chinchilla was 40 spikes per second (Hullar et al. 2005) compared to 37 spikes per second in the C57BL/6 mouse. The resting rate in monkeys has been shown to be approximately twice the resting rate in rodents (Goldberg and Fernández 1971; Sadeghi et al. 2007). The reason for this difference is not clear. One possibility is that the peak head velocity of natural head movements in monkeys is higher than in rodents, and therefore, a higher background discharge is required to prevent inhibitory cutoff.

\section{Sensitivity to head rotation}

We hypothesized that the lower rotational sensitivity in mice compared to other mammals might be due to the smaller size of the semicircular canals (Jones and Spells 1963; Hullar 2006; Yang and Hullar 2007). We predicted that the smaller canals in the mouse would produce a smaller movement of endolymph per unit of head acceleration. In turn, a smaller change in vestibular afferent firing rate would result from equivalent head accelerations. Although we did not directly measure endolymph movement, we can obtain a rough estimate by modeling the canal system as a fluid-filled duct in the torsion pendulum model first described by Steinhausen (1933). Based upon this model, we would expect the sensitivity to head velocity to vary as a function of the square of the internal radius of the membranous canal ( $r^{2}$; see Appendix). In Table 6, we compared the values of $r^{2}$ to the average sensitivity for regular and irregular afferents in the mouse, chinchilla, and the rhesus monkey. There is an approximately threefold increase in $r^{2}$ measured in the mouse in comparison to the chinchilla and monkey. This finding is very similar to the threefold

TABLE 6

The average afferent sensitivity at $2 \mathrm{~Hz}$ varies in proportion to the square of the internal radius of the semicircular canals

\begin{tabular}{lccc}
\hline Animal & Regular $\left(\mathrm{sp} \cdot \mathrm{s}^{-1}\right.$ per degree $\left.\cdot \mathrm{s}^{-1}\right)$ & Irregular $\left(\mathrm{sp} \cdot \mathrm{s}^{-1}\right.$ per degree $\left.\cdot \mathrm{s}^{-1}\right)$ & $r^{2}\left(\mathrm{~mm}^{2}\right)$ \\
\hline Mouse & $0.13 \pm 0.06$ & $0.29 \pm 0.14$ & 0.005 \\
Chinchilla & $0.48 \pm 0.52$ & $1.37 \pm 0.69$ & 0.0145 \\
Rhesus monkey & $0.50 \pm 0.31$ & $1.21 \pm 0.68$ & 0.012 \\
\hline
\end{tabular}

Values for sensitivity were obtained in the chinchilla from Hullar et al. (2005) and in the rhesus monkey from Sadeghi et al. (2007). The values for the internal radius of the chinchilla was obtained from Ramprashad et al. (1984), and the values for the mouse and rhesus monkey were obtained from Jones and Spells (1963). 
lower sensitivity of vestibular-nerve afferents in mice when compared to monkeys and chinchillas. These data suggest that $r^{2}$ may be a rough measure of afferent sensitivity among different species.

Yang and Hullar (2007) found a strong correlation between the radius of curvature of the semicircular canals and afferent sensitivity when interspecies and intraspecies comparisons were made. The intraspecies comparison was based upon data from computed tomography imaging in the mouse, demonstrating that the radius of curvature of the superior canal $(1.03 \mathrm{~mm})$ is greater than the horizontal canal (0.73 mm; Calabrese and Hullar 2006). Yang and Hullar (2007) found that the rotational sensitivity at $0.5 \mathrm{~Hz}$ for regular afferents innervating the superior canal was $0.17 \pm 0.04$ spikes per second/degrees per second, whereas the rotational sensitivity at the same frequency for horizontal canal afferents was $0.10 \pm 0.03$ spikes per second/degrees per second $(p<0.0001)$. Our data also showed a greater sensitivity for superior canal afferents $(0.14 \pm 0.04$ spikes per second/degrees per second) when compared to horizontal canal afferents $(0.11 \pm 0.04$ spikes per second/degrees per second, $p<0.001)$, although the difference was less than that observed by Yang and Hullar (2007).

The hydrodynamic model described in the Appendix suggests that the square of the internal radius of the canal is the geometric factor that influences afferent sensitivity. Previous anatomical studies have demonstrated that the radius of curvature of the canal varies in approximate proportion to its internal radius (Jones and Spells 1963). The direct relationship between the radius of curvature of the canal and the average sensitivity of regular afferents noted by Yang and Hullar (2007) can be understood based upon this relationship between internal radius and radius of curvature. There are no published data for the internal radius of each semicircular canal in the mouse; therefore, direct comparisons between individual semicircular canals and afferents are not possible in this species.

Whereas the internal radius is the geometric factor with direct influence on afferent sensitivity, the radius of curvature is the determining factor for the long time constant of afferents innervating the canal (Jones and Spells 1963). Our data revealed that the long time constant of the superior canal measured $4.3 \pm 1.2 \mathrm{~s}(n=$ 20) compared to the horizontal canal time constant of $3.1 \pm 0.6 \mathrm{~s}(n=18 ; p<0.001)$.

There is a strong correlation in most animals between the size of the internal radius of the canal, the size of the radius of curvature, and the mass of the animal (Jones and Spells 1963). In cetaceans, the radius of curvature of the canals is markedly diminished compared to their mass (Jones and Spells 1963; Spoor et al. 2002). This observation has caused some researchers to hypothesize that vestibular function should be markedly reduced in cetaceans (Spoor et al. 2002;Yang and Hullar 2007). It should be noted, however, that the internal radius $(r)$ of the semicircular canals in the common porpoise is $0.095 \mathrm{~mm}$, which is similar to that of many other mammals with comparable body mass (Jones and Spells 1963). The hydrodynamic model described in the Appendix predicts that, based upon geometrical considerations, the sensitivity of vestibular-nerve afferents at midfrequencies of rotation $(0.5-4 \mathrm{~Hz})$ in cetaceans should be comparable to that in other mammals. The consequence of the smaller radius of curvature would be a reduced long time constant of afferent sensitivity in cetaceans when compared to other mammals (Jones and Spells 1963). These relationships suggest that vestibular function is not deficient for all head rotations in cetaceans but is reduced for low-frequency head movements.

\section{Transfer function fits}

The transfer functions providing a description of the responses to rotation of vestibular afferents innervating the semicircular canals are similar in form to those that have been used to fit the data from other mammalian species (Fernández and Goldberg 1971; Baird et al. 1988; Hullar and Minor 1999; Hullar et al. 2005). A long time constant is associated with the elastic restoring force of the cupula. In addition, there is a short time constant associated with the viscous flow of endolymph. For the reasons described in the "Results," we estimated that the short time constant is approximately $0.001 \mathrm{~s}$. In addition to the two time constants associated with the mechanical properties of the cupula, there is a lead term associated with hair cell or afferent transduction. The short time constant $\left(t_{\mathrm{z}}\right)$ varies proportionally with $\mathrm{CV}^{*}$. A similar relationship has been shown in the chinchilla (Hullar et al. 2005). In that study, however, a second-order lead term was also needed to adequately fit the data. A possible explanation for the additional lead term needed in the study of Hullar et al. (2005) is that an extra pole was added to their transfer function to more closely align with the torsion pendulum model. This additional pole increased the complexity of the fit, thereby necessitating the addition of an extra lead term.

The long time constant $\left(t_{\mathrm{c} 1}\right)$ varies inversely with $\mathrm{CV}^{*}$. In our study, the value of $t_{\mathrm{c} 1}$ is approximately $3.7 \mathrm{~s}$ for regular afferents and $2.2 \mathrm{~s}$ for irregular afferents. Adaptation of responses of vestibular-nerve afferents may contribute to the differences noted in the long time constant of irregular and regular afferents. It has been shown that irregular afferents adapt much more quickly than regular afferents in 
response to very low-frequency head movements (0.001-0.01 Hz; Fernández and Goldberg 1971). This adaptation may result in an underestimate of the cupular time constant for irregular afferents. One argument against this effect is that lower estimates for the long cupular time constant for irregular in comparison to regular afferents have been found even after taking into account the consequences of adaptation (Fernández and Goldberg 1971).

\section{Dynamics of irregular afferents}

Irregular afferents in the chinchilla have been classified into calyx-only and dimorphic groups based on the morphology of their afferent endings as determined from intra-axonal recording and labeling experiments (Baird et al. 1988). The calyxonly afferents had a $\mathrm{CV}^{*} \geq 0.20$ and sensitivity to head velocity for rotations at $2 \mathrm{~Hz}, 20^{\circ} / \mathrm{s}$ of $<1.5$ spikes per second/degrees per second. This relationship has been used to assign afferents to a lowsensitivity (calyx-only) category based upon findings from extracellular recordings (Hullar et al. 2005; Sadeghi et al. 2007). Irregular afferents with $\mathrm{CV}^{*}$ and sensitivities outside these values have been classified as dimorphic afferents (Baird et al. 1988). Afferents assigned to the calyx-only category have also been shown to have a greater phase lead and a larger rise in sensitivity at high frequencies than dimorphic afferents. These dynamics can be described by a firstorder lead term with calyx-only afferents exhibiting larger values for this term than dimorphic afferents. We wanted to determine if a similar relationship could be used to describe these findings in the mouse. If this were the case, the value for $t_{\mathrm{z}}$ should rise in irregular afferents with increases in $\mathrm{CV}^{*}$ and with decreases in sensitivity at $2 \mathrm{~Hz}$. To determine if this relationship holds for afferent data recorded in mice, we fit an equation of the following form to the data from irregular afferents:

$$
\begin{aligned}
\mathrm{t}_{\mathrm{z}}= & (.076 \pm 0.015) \cdot \mathrm{CV}^{*}-(0.028 \pm 0.012) \cdot \mathrm{g}_{2} \mathrm{~Hz} \\
& +0.011 \pm 0.006\left(\mathrm{R}^{2}=0.64\right)
\end{aligned}
$$

where $t_{\mathrm{z}}=$ lead term fit for the afferent, $\mathrm{CV}^{*}=$ normalized coefficient of variation, and $g_{2} \mathrm{~Hz}=$ sensitivity at $2 \mathrm{~Hz}$. In this equation, $\mathrm{CV}^{*}$ shows a positive correlation with $t_{\mathrm{z}}(p<0.001)$, and $g_{2} \mathrm{~Hz}(p<$ $0.05)$ shows a negative correlation with $t_{\mathrm{z}}$. Conversely, dimorphic irregular afferents have lower values of $\mathrm{CV}^{*}$ and $t_{\mathrm{z}}$ but higher values for $g_{2 \mathrm{~Hz}}$. The irregular afferents recorded in our study had properties that were similar to those reported previously in chinchil- las. These findings support the notion that the relationships between morphology and physiology in the cristae of the mouse are similar to those in the chinchilla.

\section{Distribution of $\mathrm{CV}^{*}$ for juvenile and adult mice}

The bimodal distribution of afferents in adult mice with respect to discharge regularity is similar to that reported in other mammals (Baird et al. 1988; Sadeghi et al. 2007). Juvenile mice, however, have a more skewed distribution with about $30 \%$ fewer irregular afferents than in the adult mouse. The reasons for this difference are not clear. Rüsch et al. (1998) showed that the percentage of calyces in the extrastriola zone increases from $40 \%$ at postnatal day 10 to $60 \%$ at postnatal day 25 , which is consistent with a mature number (Rüsch et al. 1998). As previously described, a morphological correlation has been established between type I hair cells and irregular afferents (Baird et al. 1988). It appears unlikely, therefore, that morphological changes are accounting for the differences that we observe between juvenile and adult animals. It is interesting to note, however, that studies of regeneration of the vestibular sensory epithelia after aminoglycoside ototoxicity have shown that type I hair cells and their calyx afferent endings regenerate much later (approximately 12 weeks after ototoxic injury) in comparison to type II hair cells and bouton endings (beginning 1 week after ototoxic injury; Zakir and Dickman 2006).

Curthoys (1979) reported a larger proportion of irregular afferents in the first 3 weeks after birth in rats when compared to adult animals. The measure of discharge regularity was not normalized to the resting rate of the afferents, which complicates the interpretation of the data. The very low resting rate of afferents in newborn rats will lead to a higher value for the coefficient of variation when not normalized to a mean interval. While demonstrating age-dependent changes, the results are difficult to compare to ours because of the differences between the two studies in the ages of the animals.

\section{Responses at $2 \mathrm{~Hz}$}

A previous study in the chinchilla has shown a relationship between the morphology of vestibular afferents and their sensitivity at $2 \mathrm{~Hz}$ (Baird et al. 1988). Calyx-only (C-irregular) afferents have irregular discharge rates with low sensitivity to head velocity, whereas dimorphic afferents (D-regular, Dirregular) show a $\log -\log$ relationship between $\mathrm{CV}^{*}$ and the sensitivity to head velocity at $2 \mathrm{~Hz}$. Though 
not observed directly because of the difficulty labeling, these types of afferents, bouton-only (Bregular) afferents, are believed to be regularly discharging and to have low sensitivities to rotational head movements (Baird et al. 1988). An analysis based upon axon caliber and conduction velocity has provided support for these relationships (Lysakowski et al. 1995).

There was no difference in our study between the average sensitivity and phase for the different afferent groups at $2 \mathrm{~Hz}$ for juvenile and adult mice. There was, however, a greater variability in the sensitivity of irregular afferents at $2 \mathrm{~Hz}$ in adult animals when compared to juvenile animals. The most conspicuous difference between adult and juvenile mice was that the juvenile mice did not appear to have a separate sub-population of lowsensitivity irregular afferents. We base this conclusion on the observation that the standard deviation of afferent sensitivity at $2 \mathrm{~Hz}$ for afferents with a $\mathrm{CV}^{*}>$ 0.2 was greater in adult when compared to juvenile mice $(0.21$ compared to $0.11, p<0.001)$. A major contributor to this greater standard deviation was the larger percentage of irregular afferents with a sensitivity $<0.23$ in adult $(38 \%)$ compared to juvenile $(19 \%)$ mice. The smaller number of irregular afferents coupled with the lack of specifically low-sensitivity irregular afferents in juvenile animals suggest that some of these "calyx-only" afferents have not developed their distinctive physiologic properties.

An explanation for the differences between juvenile and adult mice may be that the sensitivity to head rotation conferred by post-synaptic mechanisms is lower in juvenile mice. Previous studies have shown a strong inverse correlation between the sensitivity at the spike-initiation site of vestibular-nerve afferents and their regularity of background discharge rate (Goldberg et al. 1984; Baird et al. 1988; Highstein et al. 2005). This post-synaptic gain has been shown in the chinchilla to be at least an order of magnitude greater in "calyx-only" afferents than in afferents that are more regularly discharging (Baird et al. 1988). A lower post-synaptic gain in juvenile animals, as suggested by our data, would make it difficult to discern a group of "calyxonly" afferents based solely on response dynamics. It is possible that these "calyx-only" afferents in juvenile animals could have either extremely low resting rates (close to zero) or low sensitivities $(<0.05$ spikes per second/degrees per second), making them difficult to identify in these experiments. In contrast, "bouton-only" and "dimorphic" afferents have larger pre-synaptic/synaptic gains, and a reduction in the post-synaptic gain would be much less discernible.

\section{ACKNOWLEDGMENT}

This work was supported by the National Institute on Deafness and Other Communication Disorders, Grant R01 DC-02390. We would like to thank Jay M. Goldberg for helpful comments on a prior version of this manuscript.

\section{APPENDIX}

The torsion pendulum model is represented by the following equation:

$$
\Theta \cdot \frac{d^{2} E}{d t^{2}}+\Pi \cdot \frac{d E}{d t}+\Delta \cdot E(t)=\Theta \cdot \frac{d v}{d t}
$$

where $E(t)$ represents the displacement of the endolymph in the semicircular canal with respect to time, $v(t)$ is the velocity of the head with respect to time, $\Theta$ is the moment of inertia of the canal, $\Pi$ is the viscous drag coefficient of the cupula and endolymph, and $\Delta$ is the elasticity coefficient of the cupula and endolymph.

Equation 7 can be converted into the following Laplace transform:

$$
\frac{E(t)}{v(t)}=\frac{\Theta \mathrm{s}}{\Theta \mathrm{s}^{2}+\Pi \mathrm{s}+\Delta}
$$

Equation 8 can then be converted into a two-pole transfer function of the following form:

$$
\frac{E(t)}{v(t)}=\frac{g_{\text {end }} \cdot t_{c 1} s}{\left(t_{\mathrm{c} 1} s+1\right)\left(t_{\mathrm{c} 2} s+1\right)}
$$

where $t_{\mathrm{c} 1}=\Pi / \Delta, t_{\mathrm{c} 2}=\Theta / \Pi$, and $g_{\text {end }}=\Theta / \Pi$

If the size of the canal plays an important role in determining the sensitivity of the response to head velocity, then we would expect to see a relationship between the mid-band sensitivity predicted from the torsion pendulum model $\left(g_{\text {end }}\right)$ and the mid-band sensitivity recorded from vestibular-nerve afferents ( $g$ in Eq. 3) in various animals. If we model the canal as a fluid-filled duct that varies only in size between species, then

$$
\begin{gathered}
\Pi=8 \eta \pi^{2} R^{3} \\
\Theta=2 \pi^{2} p \mathrm{r}^{2} R^{3}
\end{gathered}
$$

We then assume that the density $(p)$ and the viscosity $(\eta)$ will remain constant from one animal to the next. Therefore, as described by Jones and Spells 
(1963), the moment of inertia should be related to the canal dimensions:

$$
\Theta \propto r^{2} R^{3}
$$

The viscous drag coefficient of the cupula and endolymph should also be related to canal dimensions:

$$
\Pi \propto R^{3}
$$

The mid-band sensitivity from Eq. 9 is given by $g_{\text {end }}=\Theta / \Pi$. $R^{3}$ will cancel, and it follows that $g_{\text {end }}$ is expected to vary with the value of the square of the internal radius of the membranous canal $\left(r^{2}\right)$.

\section{REFERENCES}

Alagramam KN, Stahl JS, Jones SM, Pawlowski KS, Wright CG. Characterization of vestibular dysfunction in the mouse model for Usher syndrome 1F. J. Assoc. Res. Otolaryngol. 6:106-118, 2005.

Aleisa M, Zeitouni AG, Cullen KE. Vestibular compensation after unilateral labyrinthectomy: normal versus cerebellar dysfunctional mice. J. Otolaryngol. 36:315-321, 2007.

Anagnostopoulos AV. A compendium of mouse knockouts with inner ear defects. Trends Genet. 18:499, 2002.

Baird RA, Desmadryl G, Fernández C, Goldberg JM. The vestibular nerve of the chinchilla. II. Relation between afferent response properties and peripheral innervation patterns in the semicircular canals. J. Neurophysiol. 60:182-203, 1988.

Bartolomé MV, del CE, López LM, Carricondo F, Роch-Broto J, GilLoYZAGA P. Effects of aging on C57BL/6J mice: an electrophysiological and morphological study. Adv. Otorhinolaryngol. 59:106-111, 2002.

Beraneck M, Cullen KE. Activity of vestibular nuclei neurons during vestibular and optokinetic stimulation in the alert mouse. J. Neurophysiol. 98:1549-1565, 2007.

Boyden ES, Katoh A, Pyle Jl, Chatila ta, tsien RW, Raymond Jl. Selective engagement of plasticity mechanisms for motor memory storage. Neuron. 51:823-834, 2006.

Boyle R, Highstein SM. Resting discharge and response dynamics of horizontal semicircular canal afferents of the toadfish, Opsanus tau. J. Neurosci. 10:1557-1569, 1990.

Calabrese DR, Hullar TE. Planar relationships of the semicircular canals in two strains of mice. J. Assoc. Res. Otolaryngol. 7:151159, 2006.

Cullen KE, Rey CG, Guitton D, Galiana HL. The use of system identification techniques in the analysis of oculomotor burst neuron spike train dynamics. J. Comput. Neurosci. 3:347-368, 1996.

CurThoys IS. The development of function of horizontal semicircular canal primary neurons in the rat. Brain Res. 167:41-52, 1979.

De Zeeuw Ci, Hansel C, Bian F, Koekoek SK, van Alphen AM, Linden DJ, OBerdick J. Expression of a protein kinase $\mathrm{C}$ inhibitor in Purkinje cells blocks cerebellar LTD and adaptation of the vestibulo-ocular reflex. Neuron 20:495-508, 1998.

Desai SS, Ali H, Lusakowski A. Comparative morphology of the rodent vestibular periphery: II. Cristae ampullares. J. Neurophysiol. 93:267-280, 2005a.

Desai SS, Zeh C, Lysakowski A. Comparative morphology of the rodent vestibular periphery:I. Saccular and utricular maculae. J. Neurophysiol. 93:251-266, 2005b.

EATOCK RA, RÜsch A, Lysakowski A, SAeki M. Hair cells in mammalian utricles. Otalaryngol. Head Neck Surg. 119:172-181, 1998.

Faulstich BM, ONORI KA, DU LAC S. Comparison of plasticity and development of mouse optokinetic and vestibulo-ocular reflexes suggests differential gain control mechanisms. Vision Res. 44:3419-3427, 2004.

Fernández C, Goldberg JM. Physiology of peripheral neurons innervating semicircular canals of the squirrel monkey II. Response to sinusoidal stimulation and dynamics of peripheral vestibular system. J. Neurophysiol. 34:661-675, 1971.

Fernández C, Goldberg JM. Physiology of peripheral neurons innervating otolith organs of the squirrel monkey. I. Response to static tilts and to long duration centrifugal force. J. Neurophysiol. 39:970-984, 1976.

Galiana HL, Smith HL, Katsarkas A. Comparison of linear vs. nonlinear methods for analyzing the vestibulo-ocular reflex (VOR). Acta Otolaryngol. (Stockh.) 115:585-596, 1995.

GÉlÉoc GS, Risner JR, Holt JR. Developmental acquisition of voltage-dependent conductances and sensory signaling in hair cells of the embryonic mouse inner ear. J. Neurosci. 24:1114811159, 2004.

GOLDBERG JM. Afferent diversity and the organization of central vestibular pathways. Exp. Brain Res. 130:277-297, 2000.

Goldberg JM, Fernández C. Physiology of peripheral neurons innervating semicircular canals of the squirrel monkey I. Resting discharge and response to constant angular accelerations. J. Neurophysiol. 34:635-660, 1971.

Goldberg JM, Smith CE, Fernández C. Relation between discharge regularity and responses to externally applied galvanic currents in vestibular nerve afferents of the squirrel monkey. J. Neurophysiol. 51:1236-1256, 1984.

Goossens HH, Hoebeek FE, van Alphen AM, Van Der SJ, Stahl JS, De Zeeuw CI, Frens MA. Simple spike and complex spike activity of floccular Purkinje cells during the optokinetic reflex in mice lacking cerebellar long-term depression. Eur. J. Neurosci. 9:687697, 2004.

HASLWANTER T. Mathematics of three-dimensional eye rotations. Vis. Res. 35:1727-1739, 1995.

HENRY KR. Sex-and age-related elevation of cochlear nerve envelope response (CNER) and auditory brainstem response (ABR) thresholds in C57BL/6 mice. Hear. Res. 170:107-115, 2002.

Hequembourg S, Liberman MC. Spiral ligament pathology: a major aspect of age-related cochlear degeneration in C57BL/6 mice. J. Assoc. Res. Otolaryngol. 2:118-129, 2001.

Highstein SM, RabbitT RD, Boyle R. Determinants of semicircular canal afferent response dynamics in the toadfish, Opsanus tau. J. Neurophysiol. 75:575-596, 1996.

Highstein SM, Rabbitt RD, Holstein GR, Boyle RD. Determinants of spatial and temporal coding by semicircular canal afferents. J. Neurophysiol. 93:2359-2370, 2005.

Hullar TE. Semicircular canal geometry, afferent sensitivity, and animal behavior. Anat. Rec. A Discov. Mol. Cell Evol. Biol. 288:466-472, 2006.

Hullar TE, Minor LB. High-frequency dynamics of regularly discharging canal afferents provide a linear signal for angular vestibuloocular reflexes. J. Neurophysiol. 82:2000-2005, 1999.

Hullar te, Della Santina CG, Hirvonen TP, lasker DM, Carey JP, MINOR LB. Responses of irregularly discharging chinchilla semicircular canal vestibular-nerve afferents during high-frequency head rotations. J. Neurophysiol. 93:2777-2786, 2005.

Jones GM, Spells KE. A theoretical and comparative study of the functional dependence of the semicircular canal upon its physical dimensions. Proc. R. Soc. London B Biol. Sci. 157: 403-419, 1963.

Katoh A, Kitazawa H, Itohara S, Nagao S. Dynamic characteristics and adaptability of mouse vestibulo-ocular and optokinetic response eye movements and the role of the flocculo-olivary system revealed by chemical lesions. Proc. Natl. Acad. Sci. U.S.A. 95:7705-7710, 1998.

Katoh A, Yoshida T, Himeshima Y, Mishina M, Hirano T. Defective control and adaptation of reflex eye movements in mutant mice 
deficient in either the glutamate receptor delta2 subunit or Purkinje cells. Eur. J. Neurosci. 21:1315-1326, 2005.

Katoh A, Jindal JA, RaYmond JL. Motor deficits in homozygous and heterozygous p/q-type calcium channel mutants. J. Neurophysiol. 97:1280-1287, 2007.

Killian JE, BAKER JF. Horizontal vestibuloocular reflex (VOR) head velocity estimation in Purkinje cell degeneration (pcd/pcd) mutant mice. J. Neurophysiol. 87:1159-1164, 2002.

Kimpo RR, RaYMOnd JL. Impaired motor learning in the vestibuloocular reflex in mice with multiple climbing fiber input to cerebellar Purkinje cells. J. Neurosci. 27:5672-5682, 2007.

Lysakowski A, Minor lB, Fernández C, Goldberg JM. Physiological identification of morphologically distinct afferent classes innervating the cristae ampullares of the squirrel monkey. J. Neurophysiol. 73:1270-1281, 1995.

Minor LB, Lasker DM, Backous DD, Hullar TE. Horizontal vestibuloocular reflex evoked by high-acceleration rotations in the squirrel monkey. I. Normal responses. J. Neurophysiol. 82:1254-1270, 1999.

Murofushi T, Curthoys IS. Physiological and anatomical study of click-sensitive primary vestibular afferents in the guinea pig. Acta Otolaryngol. (Stockh.) 117:66-72, 1997.

Prusky GT, Alam NM, Beekman S, Douglas RM. Rapid quantification of adult and developing mouse spatial vision using a virtual optomotor system. Invest. Ophthalmol. Vis. Sci. 45:4611-4616, 2004.

RAMACHANDRAN R, LisBERGER SG. Transformation of vestibular signals into motor commands in the vestibuloocular reflex pathways of monkeys. J. Neurophysiol. 96:1061-1074, 2006.

Ramprashad F, Landolt JP, Money KE, Laufer J. Dimensional analysis and dynamic response characterization of mammalian peripheral vestibular structures. Am. J. Anat. 169:295-313, 1984.

Rüsch A, ЕАтоск RA. A delayed rectifier conductance in type I hair cells of the mouse utricle. J. Neurophysiol. 76:995-1004, 1996.

Rüsch A, Lysakowski A, Еatock RA. Postnatal development of type I and type II hair cells in the mouse utricle: acquisition of voltagegated conductances and differentiated morphology. J. Neurosci. 18:7487-7501, 1998.
SADEghi SG, Minor LB, Cullen KE. Response of vestibular-nerve afferents to active and passive rotations under normal conditions and after unilateral labyrinthectomy. J. Neurophysiol. 97:1503-1514, 2007.

Shiga A, Nakagawa T, Nakayama M, Endo T, Iguchi F, Kim TS, Naito Y, ITo J. Aging effects on vestibulo-ocular responses in C57BL/6 mice: comparison with alteration in auditory function. Audiol. Neurootol. 10:97-104, 2005.

Spoor F, Bajpai S, Hussain ST, Kumar K, Thewissen JG. Vestibular evidence for the evolution of aquatic behaviour in early cetaceans. Nature 417:163-166, 2002.

Stahl JS, van Alphen AM, De Zeeuw CI. A comparison of video and magnetic search coil recordings of mouse eye movements. J. Neurosci. Methods. 99:101-110, 2000.

Steinhausen W. Ueber die Beobachtung der Cupula in den Bogengangsampullen des Labyrinths des lebenden Hechts. Arch. Ges. Physio. 232:500-512, 1933.

Sun JC, van Alphen AM, Bohne BA, De Zeeuw CI. Shaker-1 mice show an optokinetic reflex but no vestibulo-ocular reflex. Ann. N.Y. Acad. Sci. 942:492, 2001.

Tomko DL, Peterka RJ, Schor RH, O’Leary DP. Response dynamics of horizontal canal afferents in barbiturate-anesthetized cats. J. Neurophysiol. 45:376-396, 1981.

van Alphen AM, Stahl JS, De Zeeuw CI. The dynamic characteristics of the mouse horizontal vestibulo-ocular and optokinetic response. Brain Res. 890:296-305, 2001.

van Alphen AM, Schepers T, Luo C, De Zeeuw CI. Motor performance and motor learning in Lurcher mice. Ann. N.Y. Acad. Sci. 978:413-424, 2002.

Whelan PJ. Developmental aspects of spinal locomotor function: insights from using the in vitro mouse spinal cord preparation. J. Physiol. 553:695-706, 2003.

YANG A, Hullar TE. Relationship of semicircular canal size to vestibular-nerve afferent sensitivity in mammals. J. Neurophysiol. 98:3197-3205, 2007.

ZAKIR M, DiCKMAN JD. Regeneration of vesitublar otolith afferents after ototoxic damage. J. Neurosci. 26:2881-2893, 2006. 